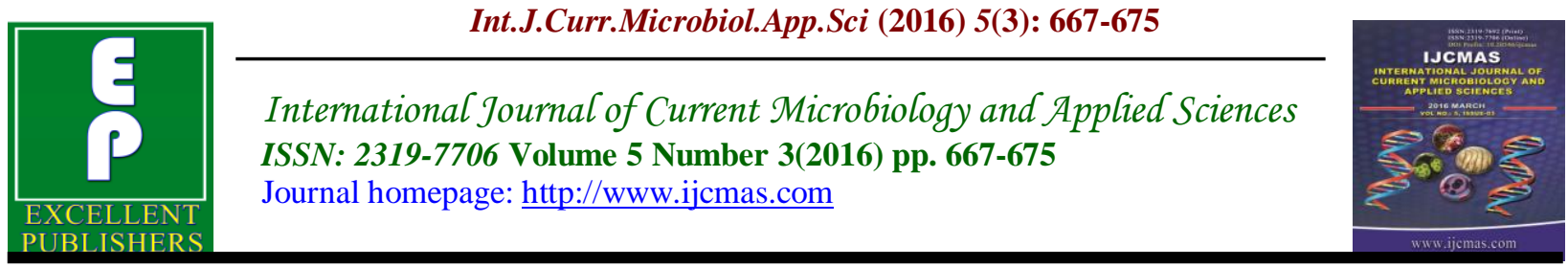

Original Research Article

http://dx.doi.org/10.20546/ijcmas.2016.503.078

\title{
Prevalence of biofilm production by Staphylococcus species isolated from patients on indwelling medical devices/implants
}

\author{
Priyanka Khanna $^{1 *}$, Pushpa Devi ${ }^{2}$ and Bimla Devi ${ }^{2}$ \\ ${ }^{1}$ Department of Microbiology, PIMS Medical College, Jalandhar, Punjab, India \\ ${ }^{2}$ Department of Microbiology, Government Medical College, Amritsar, Punjab, India \\ *Corresponding author
}

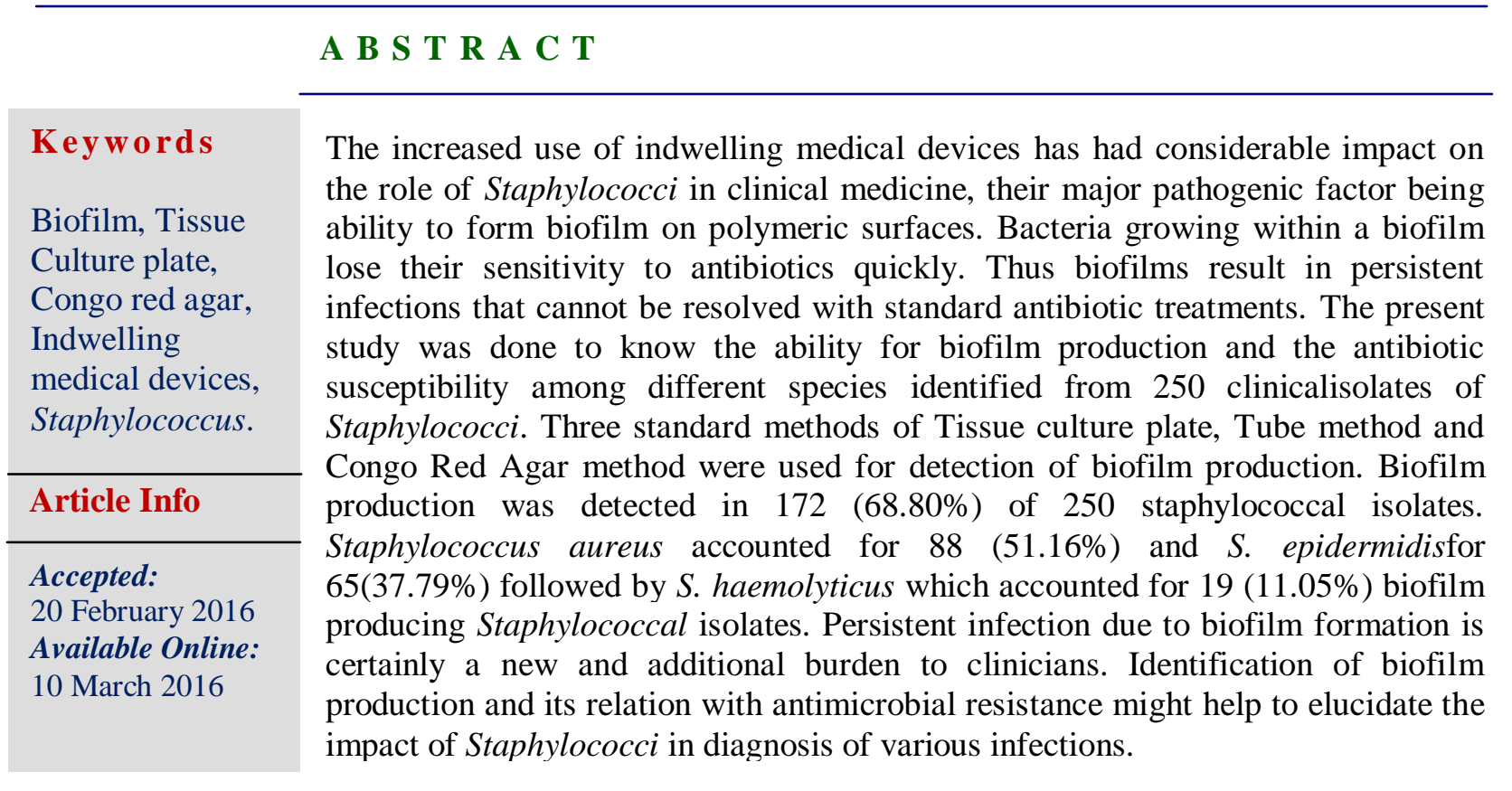

\section{Introduction}

Biofilm is an aggregate of microorganisms in which cells are stuck to each other and/or to a surface, embedded within a selfsecreted extracellular protective and adhesive matrix of a polymeric substance. Biofilm Extracellular polymeric substance (EPS), which is also referred to as slime (although not everything described as slime is a biofilm), is a polymeric conglomeration generally composed of extracellular DNA, proteins, and polysaccharides.

Biofilms are widely distributed in nature. Biofilms can form in different situations in human body, such as attachment on a surface, or after exposure to sub lethal doses of antibiotics. Such surfaces may be provided by artificial devices such as prosthetic valves, breast implants, intravenous and urinary catheters, 
intrauterine contraceptive devices or in dermatological situations like with fillers, and cheek implants.

Various microorganisms responsible for biofilm formation incude Acinatobacter baumanni, Pseudomonas aeruginosa, Klebsiella pneumoniae, E. coli, Coagulase negative Staphylococci, Enterobacter cloacae, Enterococci, and Staphylococcus aureus.

Staphylococci are most often associated with chronic infections of implanted medical devices. The use of indwelling medical devices is important in the treatment of critically and chronically ill patients, however bacterial colonization of implanted foreign material can cause major medical sequel. The increased use of indwelling medical devices has had considerable impact on the role of Staphylococci in clinical medicine, their major pathogenic factor being ability to form biofilm on polymeric surfaces.

S.aureus has an extraordinary repertoire of virulence factors that allows it to survive extreme conditions within the human host. $S$. aureus has been generally recognized to survive well both inside and outside of host cells. In the extracellular milieu, S. aureus must overcome opsonization by complement and antibodies, which directly or indirectly leads to killing of $S$. aureus. Virulence mechanisms of clinical significance include biofilm formation which allows $S$. aureus to persist on plastics and resist host defenses or antibiotics, and small colony variants which help $S$. aureus survive in a metabolically inactive state under harsh conditions. The capacity to adhere to polymer surfaces and consequent biofilm production are the main virulence factors of Coagulase negative Staphylococcus (CoNS). The biofilm protects CoNS against the action of antibiotics administered for the treatment of these infections and also against the patient's immune system.

The main objectives of this study includes isolation of Staphylococci from various clinical samples. Characterisation and identification of isolated Staphylococcito species level. Detection of biofilm formation by various standard methods. Antibiotic sensitivity testing of biofilm producing strains by Kirby Bauer disc diffusion technique.

The purpose of our study was to detect the prevalence of biofilm production in various strains ofStaphylococcus isolated from patients on indwelling medical devices and to study their antibiotic susceptibility pattern.

\section{Materials and Methods}

The present study comprised of 250 clinical isolates of Staphylococci isolated from various samples of patients with indwelling medical device admitted in hospitals attached to Government Medical College, Amritsar, Punjab, India. The various specimens collected were inoculated onto blood agar and MacConkey agar plates and incubated aerobically at $37^{\circ} \mathrm{C}$ for $18-24$ hours. Culture isolates were identified on the basis of colony, morphological, staining characteristics and various biochemical reactions $^{9}$ as per CLSI standards. Various biochemical tests namely Coagulase, Novobiocin sensitivity, Urease, acid from dMannose, PYR and Ornithine decarboxylase test were performed to identify Staphylococcus isolates to species level.

Detection of biofilm formation was done by various standard methods described as:

Tissue Culture Plate (TCP) method: Strains isolated from fresh agar plates were inoculated in Brain Heart Infusion (BHI) 
broth with $2 \%$ sucrose. Broth was incubated for 24 hours at $37^{\circ} \mathrm{C}$. The broth culture was diluted 1 in 100 with fresh medium. Individual wells of sterile, polystyrene, 96 well-flat bottom tissue culture plates were filled with $0.2 \mathrm{ml}$ diluted cultures. The tissue culture plates were incubated for 18 hours to 24 hours at $37^{\circ} \mathrm{C}$. After incubation content of each well was gently removed by tapping the plates. The wells were washed four times with phosphate buffer saline (PBS pH 7.2). Biofilms formed by adherent 'sessile' organisms in plate were fixed with sodium acetate $(2 \%)$ and stained with crystal violet $(0.1 \%)$. Excess stain was rinsed off by thorough washing with deionized water and plates were dried. Optical density (OD) of stained adherent bacteria were determined with a micro ELISA reader. These OD values were considered as an index of bacteria adhering to surface and forming biofilm. OD values greater than 0.240 were taken as Strong biofilm producer. OD values less than 0.120 as non-biofilm producer and those $\mathrm{b} / \mathrm{w} 0.120-0.240$ were taken as moderate biofilm producers.

Tube Method $(\mathrm{TM})^{5}$ :Brain heart infusion media wth $2 \%$ sucrose wasinoculated with loopful of microorganism from overnight culture plates and incubated for 24 hours at $37^{\circ} \mathrm{C}$. The tubes were decanted and washed with PBS ( $\mathrm{pH} 7.3$ ) and dried. Dried tubes were stained with crystal violet $(0.1 \%)$. Excess stain was removed and tubes were washed with deionized water. Tubes were then dried in inverted position and observed for biofilm formation.Biofilm formation was considered positive when a visible film lining the wall and bottom of the tube was present.

Congo Red Agar (CRA) Method: Congo red was prepared as concentrated aqueous solution and autoclaved at $121^{\circ} \mathrm{C}$ for 15 minutes, separately from other medium constituents. Agar was cooled to $55^{\circ} \mathrm{C}$ and then congo red was added. Plates were inoculated and incubated aerobically for 2448 hours at $37^{\circ} \mathrm{C}$. Positive result was indicated by black colonies with a dry crystalline consistency. A darkening of the colonies with the absence of dry crystalline colonial morphology indicated an intermediate result.

Susceptibility testing against CLSI recommended antibiotics was performed by Kirby Bauer disk diffusion method in these biofilm producing isolates.

\section{Results and Discussion}

The present study was conducted on 250 isolates of Staphylococcus species isolated from various clinical specimens received from hospitalized patients with an indwelling medical device in the department of Microbiology, Govt. Medical College Amritsar.

Maximum isolates were from pus 107 $(42.80 \%)$ followed by urine $73(29.20 \%)$, vaginal swabs $24(9.60 \%)$, blood $15(6 \%)$ and majority of isolates were of Staphylococcus aureus 139 (55.60\%) followed by Staphylococcus epidermidis 75 (30.00\%) (Table I). Among 111 coagulase negative Staphylococcus spp. majority of the isolates were of S. epidermidis $75(30 \%)$ followed by $S$. hemolyticus30 (12\%) and $S$. saprophyticus $6(2.4 \%)$ (Table II).

All Staphylococcal isolates were tested for biofilm formation by three methods (TCP, TM and CRA). 172 (68.80\%) isolates were detected to be biofilm producers (Table III) by TCP method whereas TM detected biofilm production in 150 isolates $(60 \%)$ and only $78(31.20 \%)$ isolates were detected positive for biofilm production by CRA method. Incidence of biofilm production 
was studied in all the four species of Staphylococcus isolated in our study. Out of 75 S. epidermidis isolates $65(86.67 \%)$ were found to be positive for biofilm production. This was followed by $88 \mathrm{~S}$. aureus isolates among 139 (63.76\%) and 19 S. hemolyticus isolates $(63.33 \%)$ found as biofilm producers. None of the $S$. saprophyticus $(0 \%)$ showed biofilm production(Table IV).Clinical isolates of biofilm producing Staphylococci showed maximum sensitivity to Linezolid (97.7\%) and Vancomycin (95.5\%) followed by Amikacin (87.5\%) (Table V).

Table.1 Species Distribution of Staphylococci

\begin{tabular}{|l|l|l|}
\hline Species & Cases & Percentage (\%) \\
\hline Staphylococcus aureuus & 139 & 55.60 \\
\hline Staphylococcus epidermidis & 75 & 30.00 \\
\hline Staphylococcus haemolyticus & 30 & 12.00 \\
\hline Staphylococcus saprophyticus & 06 & 2.40 \\
\hline Total & 250 & 100.00 \\
\hline
\end{tabular}

$x^{2}=13.662 ; d f=3 ; p=0.003$; Significant

Table.2 Species Distribution amongst Coagulase Negative Staphylococci

\begin{tabular}{|l|l|l|}
\hline CoNS & Cases & Percentage (\%) \\
\hline Staphylococcus epidermidis & 75 & 67.57 \\
\hline Staphylococcus haemolyticus & 30 & 27.02 \\
\hline Staphylococcus saprophyticus & 06 & 05.41 \\
\hline Total CoNS & 111 & 100.00 \\
\hline
\end{tabular}

$x^{2}=10.692 ; \mathrm{df}=2 ; \mathrm{p}=0.005 ;$ Significant

Table.3 Distribution of Detection of Biofilm Production by the Three Methods in Isolates from Patients with Indwellin Medical Device

\begin{tabular}{|c|c|c|c|c|c|c|}
\hline \multirow[t]{2}{*}{ Biofilm production } & \multicolumn{6}{|c|}{ Detection method } \\
\hline & \multicolumn{2}{|c|}{$\mathrm{TCP}(\mathrm{n} / \%)$} & \multicolumn{2}{|c|}{ TM (n/\%) } & \multicolumn{2}{|c|}{ CRA (n/\%) } \\
\hline $\mathrm{HIGH}^{*}$ & 70 & $28.00 \%$ & 51 & $20.40 \%$ & 28 & $11.20 \%$ \\
\hline MODERATE** & 102 & $40.80 \%$ & 99 & $39.60 \%$ & 50 & $20.00 \%$ \\
\hline NON/WEAK*** & 78 & $31.20 \%$ & 100 & $40.00 \%$ & 172 & $70.40 \%$ \\
\hline
\end{tabular}

$* \mathrm{OD}>0.240$

$* * \mathrm{OD} \mathrm{b} / \mathrm{w} 0.120-0.240$

$* * * \mathrm{OD}<0.120$

For TCP, $x^{2}=3.859 ; \mathrm{df}=1 ; \mathrm{p}=0.048$; Significant

For CRA, $x^{2}=70.682$; df $=1$; $p<0.001$; Highly Significant 
Table.4 Biofilm Production by Different Staphylococcal Species

\begin{tabular}{|l|l|l|l|}
\hline \multicolumn{1}{|c|}{ Isolate } & Biofilm Producers & \multicolumn{1}{|c|}{$\begin{array}{c}\text { Non-Biofilm } \\
\text { producers }\end{array}$} & Percentage (\%) \\
\hline Staphylococcus aureus $\mathrm{n}=139$ & 88 & 51 & 63.31 \\
\hline Staphylococcus epidermidis $\mathrm{n}=75$ & 65 & 10 & 86.67 \\
\hline Staphylococcus haemolyticus $\mathrm{n}=30$ & 19 & 11 & 63.33 \\
\hline Staphylococcus saprophyticus $\mathrm{n}=06$ & 00 & 06 & 00.00 \\
\hline Total $\mathrm{n}=250$ & 172 & 78 & 68.80 \\
\hline
\end{tabular}

$\mathrm{x}^{2}=19.518 ; \mathrm{df}=3 ; \mathrm{p}<0.001$; Highly Significant

Table.5 Antibiotic Sensitivity Pattern in Biofilm Producing Staphylococcus Isolates

\begin{tabular}{|c|c|c|c|c|c|c|c|c|c|c|c|}
\hline \multirow[t]{2}{*}{ Isolate } & AK & $\mathrm{G}$ & A & $\mathrm{CF}$ & $\mathrm{Cs}$ & $\mathrm{E}^{*}$ & $\mathrm{~N}^{* *}$ & NR** & $\mathrm{Cx}$ & $\mathrm{Va}$ & $\mathrm{LZ}$ \\
\hline & $\mathrm{n} / \%$ & $\mathrm{n} / \%$ & $\mathrm{n} / \%$ & $\mathrm{n} / \%$ & $\mathrm{n} / \%$ & $\mathrm{n} / \%$ & $\mathrm{n} / \%$ & $\mathrm{n} / \%$ & $\mathrm{n} / \%$ & $\mathrm{n} / \%$ & $\mathrm{n} / \%$ \\
\hline $\begin{array}{l}\text { S.aureus } \\
\mathrm{n}=88\end{array}$ & $\begin{array}{l}77 / \\
87.50\end{array}$ & $\begin{array}{l}25 / \\
28.41\end{array}$ & $\begin{array}{l}11 / \\
12.50\end{array}$ & $\begin{array}{l}15 / \\
17.05\end{array}$ & $\begin{array}{l}13 / \\
14.7 \\
7 \\
\end{array}$ & $\begin{array}{l}17 / \\
25.7 \\
5 \\
\end{array}$ & $\begin{array}{l}14 / \\
63.6 \\
3 \\
\end{array}$ & $\begin{array}{l}10 / \\
45.45\end{array}$ & $\begin{array}{l}23 / \\
26.1 \\
4 \\
\end{array}$ & $\begin{array}{l}84 / \\
95.4 \\
5 \\
\end{array}$ & $\begin{array}{l}86 / \\
97.7 \\
2 \\
\end{array}$ \\
\hline $\begin{array}{l}\text { S.epiderm } \\
\text { idis } \\
\mathrm{n}=65\end{array}$ & $\begin{array}{l}53 / \\
81.54\end{array}$ & $\begin{array}{l}18 / \\
27.70\end{array}$ & $\begin{array}{l}13 / \\
14.77\end{array}$ & $\begin{array}{l}12 / \\
13.64\end{array}$ & $\begin{array}{l}09 / \\
10.2 \\
3 \\
\end{array}$ & $\begin{array}{l}13 / \\
31.7 \\
1 \\
\end{array}$ & $\begin{array}{l}10 / \\
41.6 \\
7 \\
\end{array}$ & $\begin{array}{l}09 / \\
37.50\end{array}$ & $\begin{array}{l}21 / \\
32.3 \\
1 \\
\end{array}$ & $\begin{array}{l}62 / \\
95.3 \\
8 \\
\end{array}$ & $\begin{array}{l}61 / \\
93.8 \\
4 \\
\end{array}$ \\
\hline $\begin{array}{l}\text { S.haemol } \\
\text { yticus } \\
n=19\end{array}$ & $\begin{array}{l}14 / \\
73.68\end{array}$ & $\begin{array}{l}08 / \\
42.11\end{array}$ & $\begin{array}{l}01 / \\
5.26\end{array}$ & $\begin{array}{l}06 / \\
5.26\end{array}$ & $\begin{array}{l}03 / \\
15.7 \\
8\end{array}$ & $\begin{array}{l}02 / \\
13.3 \\
3\end{array}$ & $\begin{array}{l}03 / \\
75.0 \\
0\end{array}$ & $\begin{array}{l}04 / \\
100.0 \\
0\end{array}$ & $\begin{array}{l}08 / \\
42.1 \\
1\end{array}$ & $\begin{array}{l}16 / \\
84.2 \\
1\end{array}$ & $\begin{array}{c}18 / \\
94.7 \\
3\end{array}$ \\
\hline
\end{tabular}

AK-Amikacin, G-Gentamicin, A-Ampicillin, CF-Ciprofloxacin, Cs-Cephalexin, E-Erythromycin, N-Nitrofurantoin, NR-Norfloxacin, Cx-Cefoxitin, Va-Vancomycin, LZ-Linezolid

* not applied for urine samples

** was applied for urine sample only

Figure.1 Congo Red Agar Plate with Biofilm Producing and Non-Biofilm Producing Strains

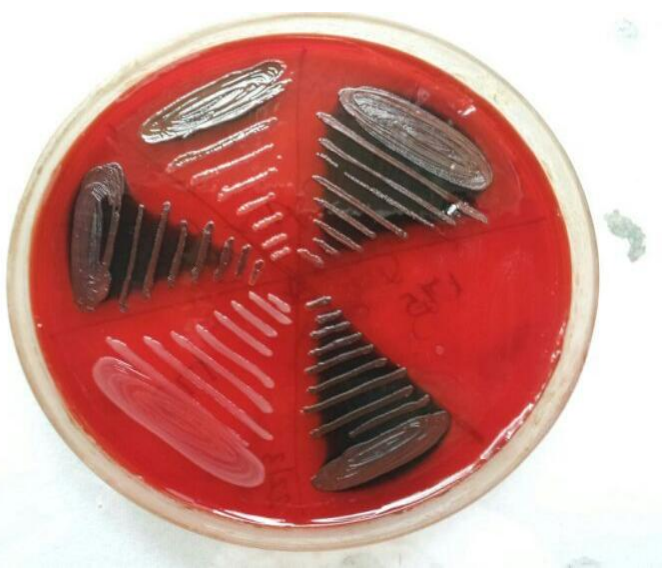


Figure.2 Tube Method

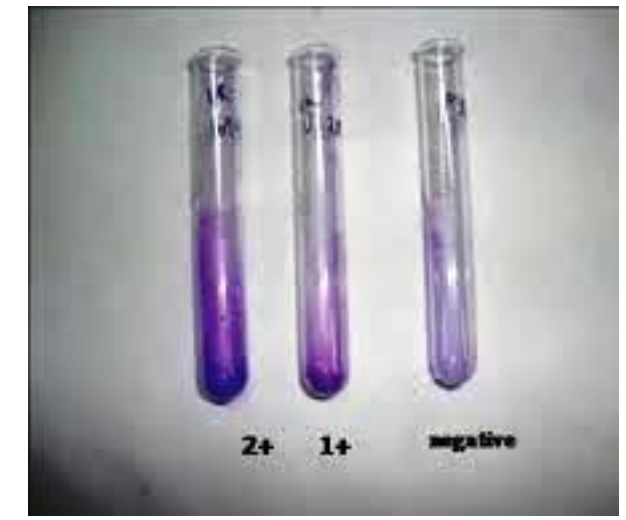

Figure.3 Tissue Culture Plate Method

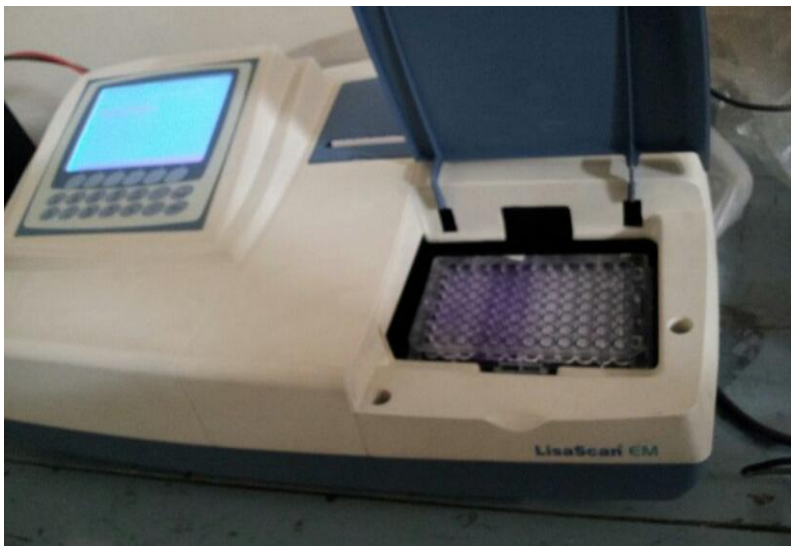

Biofilm has been described as a barrier, which is produced by microorganisms to survive and protect themselves against various environments. Biofilm production is an important mechanism that allows microbes to escape host defenses and antimicrobial therapy. Biofilm formation on indwelling medical devices and implants such as catheters, mechanical heart valves, pacemakers, prosthetic joints, and contact lenses pose a critical medical problem. Staphylococcus sp. is a common cause of nosocomial and environmental infection. It has been thought that testing for biofilm formation could be a useful marker for the pathogenicity of Staphylococci. Staphylococcus is known for its ability to produce biofilm which is considered to be an important virulence factor as well as one of the mechanisms for antimicrobial resistance. Identification of biofilm production and its relation with antimicrobial resistance might help to elucidate the impact of Staphylococci in diagnosis of various infections.

The maximum number of Staphylococcus isolates were from pus i.e., 107 (42.80\%) followed by urine $(29.20 \%)$, vaginal swabs $(9.60 \%)$ and blood $(6.00 \%)$ in patients with indwelling medical device. The findings are similar to the study conducted by Munesh Kumar Gupta et al Rajaduraipandi et al with maximum isolates from clinical specimens of pus followed by blood and urine.Staphylococcus aureus was the most common species isolated i.e. 139(55.20\%). The role of $S$. aureus as a human pathogen is widely known fact supporting our finding as its main causative role in infections. This is 
consistent with the study done by MullaSummaiya A and Jethwani Urmi N on ventilator associated pneumonia in whichS. aureus was the leading Gram positive organism isolated. However Iorio N.L et al in their study isolated lesser perecentage of Staphylococcus aureus strains. Staphylococcus epidermidiswas the second most common species followed by Staphylococcus haemolyticus isolated in the present study. This difference among CoNS species was statistically significant $(\mathrm{p}=$ 0.005).This was in concordance with the study done by Iorio N.L et al who found S.epidermidis as the most common species isolated in their study.

The biofilm formation has been documented as survival strategy of pathogens. It has been well documented that biofilms add to the virulence of the pathogen. 172/250 (68.80\%) Staphylococcal isolates were found to be positive for biofilm production. It has been estimated that the frequency of infections caused by biofilms, especially in developed world, lies between $65 \%$ and $80 \%$ as per reports from centres for disease control and prevention (CDC) and National Institute of Health (NIH), respectively. Biofilm production was detected by the three standard methods i.e., Tissue Culture Plate (TCP), Tube Method (TM) and Congo Red Agar (CRA) methods.

Whereas TCP detected biofilm production in $68.80 \%$ of the clinical isolates, TM could detect it in $60 \%$. The tube method correlated well with strong biofilm production but it was not able to detect weak production. These observations were similar to the one made by $\mathrm{T}$ Mathur in his study on an evaluation of the three screening methods. However a study by Adilson Oliveira found TM to be highly sensitive and highly specific for the detection of biofilm production. This can be due to observer variation in detection of biofilm by TM. Moreover in their study, they compared the TM against PCR which detects the presence of icaA and icaD or icaACD genes.

The CRA method failed to correlate well with TCP and TM in our study. CRA detected biofilm production in only 78 of the 250 clinical isolates $(31.20 \%)$. These observations were found to be highly significant $(p<0.001)$ against $\mathrm{CRA}$. This was in concordance with the studies of T Mathur, Silva et al and YasmeenTaj et al. However these observations were entirely in diasagreement with observations reported by Freeman DJ et al and Munish Kumar Gupta et al who found CRA as more sensitive method for biofilm detection. But according to findings of our present study CRA did not correlate well with TCP and TM. TCP method was found to be the most sensitive followed by TM.

The biofilm formation has been observed in the clinical isolates of Staphylococcus aureus. Maximum biofilm production was seen in Staphylococcus aureus $(51.16 \%)$ and $S$. epidermidis $(43.60 \%)$ followed by $S$. haemolyticus (11.05\%). This difference was statistically found to be highly significant(p $<0.001)$. This observation is in concordance with $\mathrm{T}$ Mathur who observed biofilms in $53.9 \%$ Staphylococcal isolates. However $S$. epidermidis was the most frequently detected species $(81 \%)$ by Adilson Oliveira in their study. But this difference was perhaps due to the fact that their study was concentrated on coagulase negative Staphylococci and he found this observation amongst CoNS. In our study S. aureus was the most common species identified. Amongst CoNS, in our study also $S$. epidermidis was the most common species isolated accounting for $67.57 \%$ biofilm producing CoNS. Similarly Elizabeth Fredheim et al found greater prevalence of 
biofilm production by $S$. haemolyticus as their study included only $S$. haemolyticus strains.

Biofilms act as virulence factor for the pathogen. Greater resistance was observed to all antimicrobial drugs in the biofilm producing isolates. Maximum resistance was observed for ampicillin (85.46\%) while resistant strains to cefoxitin were $66.86 \%$. Vancomycin and Linezolid resistance was observed in $5.81 \%$ and $4.07 \%$ of the biofilm producing Staphylococcal isolates, respectively. The results were consistent with the study conducted by Nizami Duran that showed a high level of resistance among the staphylococal isolates to most of the commonly used antimicrobials.

In conclusion, Biofilm production is one of the virulence factor of Staphycococcus and should be looked for along with coagulase production and other virulence factors. This trait is responsible for chronicity of infections and persistence of these organisms in infection sites and hospital environment. Biofilm forming capacity among Staphylococci in association with invasive devices is significant addition to the list of other contributory virulent factors like coagulase, toxin production and antibiotic resistance and it has accelerated the emergence of Staphylococci as a global human pathogen. This must be looked for along with other virulence factors. This may contribute to the increased hospital stay, patient's morbidity, mortality and increased health care cost associated with invasive devices.

Most common organism isolated among various isolates was Staphylococcus aureus $(55.60 \%)$ followed by Staphylococcus epidermidis (30.00\%). Most common species amongst coagulase negative Staphylococci was found to be S. epidermidis 75/111 (67.57\%).

Tissue culture plate (TCP) method was observed to be highly sensitive for detection of biofilm production with detection rate of $68.80 \%$.

Biofilm production was detected in 172 out of 250 isolates i.e. $68.80 \%$. Most common species amongst which biofilm production was detected was Staphylococcus epidermidis $(86.67 \%)$.

\section{References}

Adriana N. De Paulis et al. Five-Test Simple Scheme for Species-Level Identification of Clinically Significant CoagulaseNegative Staphylococci. J ClinMicrobiol. 2003 March; 41(3): 1219-24.

Bauer AW, Kirby WMM et al. Antibiotic susceptibility testing by a standardized single disc method. Am J Clin Path 1966;45:493-6.

Chen M, Qingsong $\mathrm{Y}$ and Sun H. Novel Strategies for the Prevention and Treatment of Biofilm Related Infections. Int. J. Mol. Sci. 2013; 14:18488-18501

Collee JG, Marr W. Specimen collection, culture containers and media. In: Collee JG, Fraser AG, Marmion BP, Simmons A, editors. Mackie \& McCartney Practical Medical Microbiology. 14th ed. New Delhi: Elsevier, a division of Reed Elsevier India Pvt. Ltd.; 2006:95-111.

De Silva GDI et al. The ica Operon and Biofilm production in coagulase-negative Staphylococci Associated with carriage and disease in Neonatal Intensive Care unit. J ClinMicrobiol. 2002; 40(2):382-8.

Donlan R.M, Biofilms: Microbial life on surfaces. Emerg Infect dis 2002; 881-890.

Duran N, Ozer B, Duran G.G, OnlenYandDemir C. Antibiotic resistance genes \& susceptibility patterns in staphylococci. Indian J Med Res 2012;135: 389-396. 
Elizabeth Gladys AaragFredheim, Claus Klingenberg, Holger Rohde, Stephanie Frankenberger, Peter Gaustad, TrondFlægstad and Johanna Ericson Sollid. Biofilm Formation by Staphylococcus haemolyticus. J Clin Microbiol, 2009 April; 47(4): 1172-1180.

Foster TJ. Immune evasion by staphylococci. Nat Rev Microbiol 2005; 3:948-58.

Freeman DJ, Falkner FR, Keane CT: New method for detecting slime production by coagulase-negative staphylococci.J ClinPathol 1989, 42:872-874.

Gupta M.K et al. Biofilm: Detection Methods and Correlation with Antimicrobial Resistance in Staphylococcus. National Journal of Laboratory Medicine. 2013; 2(2): 7-10.

Hall-Stoodley L, Costerton JW, Stoodley P. Bacterial biofilms: From the natural environment to infectious diseases. Nat Rev Microbiol 2004;2:95-108.

Kloos WE, Bannerman TL. Update on clinical significance of coagulase negative Staphylococci. ClinMicrobiol Rev. 1994;7:117-40.

Mathur T, Singhal S et al. Detection of biofilm formation among the clinical isolates of Staphylococci: An evaluation of three different screening methods. Indian J Med Microbiol. 2006;24:25-9.

Mulla SA, Revdiwala S. Assessment of biofilm formation in device-associated clinical bacterial isolates in a tertiary level hospital. Indian J PatholMicrobiol. 2011;54:561-4.

Natalia L. P. Iorio et al. Methicillin-resistant Staphylococcus epidermidis carrying biofilm formation genes: detection of clinical isolates by multiplex PCR.
International Microbiology 2011; 14:1317.

Oliveira A, Cunha RS. Comparison of methods for the detection of biofilm production in coagulase-negative staphylococci. BMC Research Notes 2010, 3:260

Parsek MR, Singh PK. Bacterial biofilms: An emerging link to disease pathogenesis. Annu Rev Microbiol 2003;57:677-701.

Rajesh Sawhney, Vandana Berry, Bacterial Biofilm Formation, Pathogenicity, Diagnostics and Control: An Overview, Indian J Med Sci, 2009; 6.

Sadashivaiah AB, Mysore V. Biofilms: Their Role in Dermal Fillers. J CutanAesthetSurg . 2010;3(1):20-1.

Stoll BJ, Hansen $\mathrm{N}$ et al: Late-onset sepsis in very low birth weight neonates: the experience of the NICHD Neonatal Research Network. Pediatric 2002, 110:285-291.

Summaiya A. M, Jethwani U. N. Assesment of Biofilm Formation by the Causative Organisms of Ventilator Associated Pneumonia at intensive care unit of a tertiary care hospital. National journal of medical research. 2012; 2(1):15-18.

Watnick P and Kolter R. Biofilm, city of microbes. J Bacteriol, 182; 2000:2675-79.

Wayne PA. Clinical and laboratory standard institute 2006. Performance standards for antimicrobial disc tests. Approved Standards, $9^{\text {th }}$ ed.; sixteenth informational supplement. M2-A9 2006;26.

Yasmeen T, Farhan E et al. Study on biofilmforming properties of clinical isolates of Staphylococcus aureus.J Infect DevCtries2012; 5(6):403-409.

\section{How to cite this article:}

Priyanka Khanna, Pushpa Devi and Bimla Devi. 2016. Prevalence of biofilm production by Staphylococcus species isolated from patients on indwelling medical devices/implants. Int.J.Curr.Microbiol.App.Sci.5(3): 667-675. doi: http://dx.doi.org/10.20546/ijcmas.2016.503.078 